Article

\title{
Discrimination of Transgenic Canola (Brassica napus L.) and their Hybrids with B. rapa using Vis-NIR Spectroscopy and Machine Learning Methods
}

\author{
Soo-In Sohn ${ }^{1, *(\mathbb{D})}$, Subramani Pandian ${ }^{1,+}+\mathbb{D}$, John-Lewis Zinia Zaukuu ${ }^{2,+}{ }^{+}$, Young-Ju Oh ${ }^{3,+}$, Soo-Yun Park ${ }^{1,+}$,

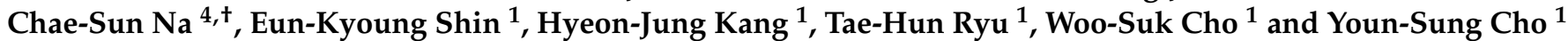 \\ 1 Department of Agricultural Biotechnology, National Institute of Agricultural Sciences, Rural Development \\ Administration, Jeonju 54874, Korea; pandiannsp7@gmail.com (S.P.); psy22@korea.kr (S.-Y.P.); \\ novis7@korea.kr (E.-K.S.); happykorean@korea.kr (H.-J.K.); thryu@korea.kr (T.-H.R.); \\ phyto@korea.kr (W.-S.C.); younsung@korea.kr (Y.-S.C.) \\ 2 Department of Food Science and Technology, Kwame Nkrumah University of Science and Technology (KNUST), \\ Kumasi AK-039-5028, Ghana; izaukuu@yahoo.com \\ 3 Institute for Future Environmental Ecology Co., Ltd., Jeonju 54883, Korea; 50joo@hanmail.net \\ 4 Seed Conservation Research Division, Baekdudewgan National Arboretum, Bonghwa 36209, Korea; \\ chaesun.na@kiam.or.kr \\ * Correspondence: sisohn@korea.kr; Tel.: +82-063-238-4712 \\ + These authors contributed equally to this work.
}

Citation: Sohn, S.-I.; Pandian, S.; Zaukuu, J.-L.Z.; Oh, Y.-J.; Park, S.-Y.; Na, C.-S.; Shin, E.-K.; Kang, H.-J.;

Ryu, T.-H.; Cho, W.-S.; et al.

Discrimination of Transgenic Canola (Brassica napus L.) and their Hybrids with B. rapa using Vis-NIR

Spectroscopy and Machine Learning Methods. Int. J. Mol. Sci. 2022, 23, 220 https://doi.org/10.3390/ijms23010220

Academic Editors: Ian A. Nicholls and Vladimir N. Uversky

Received: 4 November 2021

Accepted: 22 December 2021

Published: 25 December 2021

Publisher's Note: MDPI stays neutral with regard to jurisdictional claims in published maps and institutional affiliations.

Copyright: (c) 2021 by the authors. Licensee MDPI, Basel, Switzerland. This article is an open access article distributed under the terms and conditions of the Creative Commons Attribution (CC BY) license (https:// creativecommons.org/licenses/by/ $4.0 /)$.

\begin{abstract}
In recent years, the rapid development of genetically modified (GM) technology has raised concerns about the safety of GM crops and foods for human health and the ecological environment. Gene flow from GM crops to other crops, especially in the Brassicaceae family, might pose a threat to the environment due to their weediness. Hence, finding reliable, quick, and low-cost methods to detect and monitor the presence of GM crops and crop products is important. In this study, we used visible near-infrared (Vis-NIR) spectroscopy for the effective discrimination of GM and non-GM Brassica napus, B. rapa, and F1 hybrids (B. rapa X GM B. napus). Initially, Vis-NIR spectra were collected from the plants, and the spectra were preprocessed. A combination of different preprocessing methods (four methods) and various modeling approaches (eight methods) was used for effective discrimination. Among the different combinations, the Savitzky-Golay and Support Vector Machine combination was found to be an optimal model in the discrimination of GM, non-GM, and hybrid plants with the highest accuracy rate (100\%). The use of a Convolutional Neural Network with Normalization resulted in $98.9 \%$. The same higher accuracy was found in the use of Gradient Boosted Trees and Fast Large Margin approaches. Later, phenolic acid concentration among the different plants was assessed using GC-MS analysis. Partial least squares regression analysis of Vis-NIR spectra and biochemical characteristics showed significant correlations in their respective changes. The results showed that handheld Vis-NIR spectroscopy combined with chemometric analyses could be used for the effective discrimination of GM and non-GM B. napus, B. rapa, and F1 hybrids. Biochemical composition analysis can also be combined with the Vis-NIR spectra for efficient discrimination.
\end{abstract}

Keywords: Brassica rapa; transgenic canola; GM detection; Vis-NIR spectroscopy; chemometrics; machine learning

\section{Introduction}

Oilseed rape (Brassica napus L.), also known as canola, is one of the most important oil crops, belongs to the Brassicaceae family which has 338 genera and 3709 species [1]. It produces 75 million tonnes per year of oil globally, among which approximately $60 \%$ of rapeseed oil is used for food, $38 \%$ for industrial uses, and 3\% for feed [2]. B. napus (AACC, $2 \mathrm{n}=38$ ) originated by natural hybridization between two diploid progenitors, B. rapa (AA, 
$2 \mathrm{n}=20)$ and B. oleracea $(C C, 2 \mathrm{n}=18)$ in the Mediterranean region about 7500 years ago $[3,4]$. Introgression of genes from $B$. rapa and synthetic materials produced by artificial crossing between the two diploid progenitors have broadened the genetic pool of $B$. napus $[5,6]$. Since it is closely related to several weeds and wild species and produces a large amount of pollen, when it has favorable conditions, it attains a significant degree of outcrossing $(20-40 \%)[7,8]$. Several studies have reported on the hybridization of B. napus with close relative species, among which $B$. rapa is the most common $[8,9]$.

In the last three decades, GM technologies have introduced various novel characteristics into B. napus including increased oil content [10], drought resistance [11], herbicide resistance [12], and the production of bioactive compounds [13]. Farmers have adopted transgenic canola for its potential advantages, but the coexistence of transformants and nontransformants poses a threat to the inserted transgene spreading [14]. B. napus can grow on both wasteland and agricultural fields, and may develop feral wild populations that can serve as pollen donors and acceptors $[15,16]$. The introduction of GMOs in agricultural and food markets should be accompanied by a regulatory body to monitor the presence and quantity of GMOs. Nowadays, there are a lot of analytical methods for determining, characterization, and verifying GMOs in crops and foods. There ae DNA-based methods like Southern blot, qualitative and quantitative PCR, and real-time PCR, and protein-based methods like Western blot, ELISA, and lateral flow strip [17,18]. Overall, GMO detection approaches based on DNA and proteins are flexible, sensitive, and accurate. Nevertheless, these methods are laborious, expensive, time-consuming and require highly qualified professionals. Conversely, spectroscopy methods are nondestructive, synchronous, and involve consistent detection instruments that are environmentally benign, quick $(<1 \mathrm{~min})$, low-cost, and simple to use without requiring complicated sample preparation [17].

The use of near-infrared (NIR) and visible NIR (Vis-NIR) spectroscopy combined with chemometric analyses has resulted in effective discrimination of GMOs in agro-food markets [18]. Vis-NIR spectroscopy is most common in the detection of GMOs used with the spectral range of 350-2500 $\mathrm{nm}$ (Visible (350-780) and NIR (780-2500)) overlapping with the optical radiation range $(100-1000 \mathrm{~nm})[18,19]$. It works on the principle of identifying the relative proportions of $\mathrm{C}-\mathrm{H}, \mathrm{N}-\mathrm{H}$, and $\mathrm{O}-\mathrm{H}$ bonds in organic molecules. Detection of GMOs using Vis-NIR spectroscopy is not based on the detection of changes in DNA or single proteins but on identifying the changes in structural changes due to the genotype changes caused by the introduction of transgenes for target traits [17]. Previously, several research projects were successful in using Vis-NIR spectroscopy and chemometric approaches for the effective discrimination of GM crops and foods [18,20-22]. Further, it is important to assess the biochemical compositional changes in the transgenic plants [23]. This can provide a correlation between spectral data prediction and the chemical composition [24]. Hence, in the present study, we aimed to explore the feasibility of effective discrimination between GM and non-GM B. napus, and their hybrids with B. rapa (B. rapa X GM B. napus), by using Vis-NIR spectroscopy in combination with different preprocessing and machine learning methods and assessing the phenolic compounds using GC-MS analysis.

\section{Results}

\subsection{Diffuse Reflectance Spectroscopic Analysis and Preprocessing}

The original raw spectra of the B. napus, GM B. napus, B. rapa and the F1 hybrids were collected in the green house. The original raw spectra were those that had not been preprocessed in any way and the average raw spectra are shown in Figure 1A. Further, the spectra from all the plants were preprocessed with three different methods, namely, Savitzky-Golay smoothing filter (21-points), Normalization, Standard Normal Variate and averaged, as shown in Figures $1 B$ and 2C,D, respectively. 

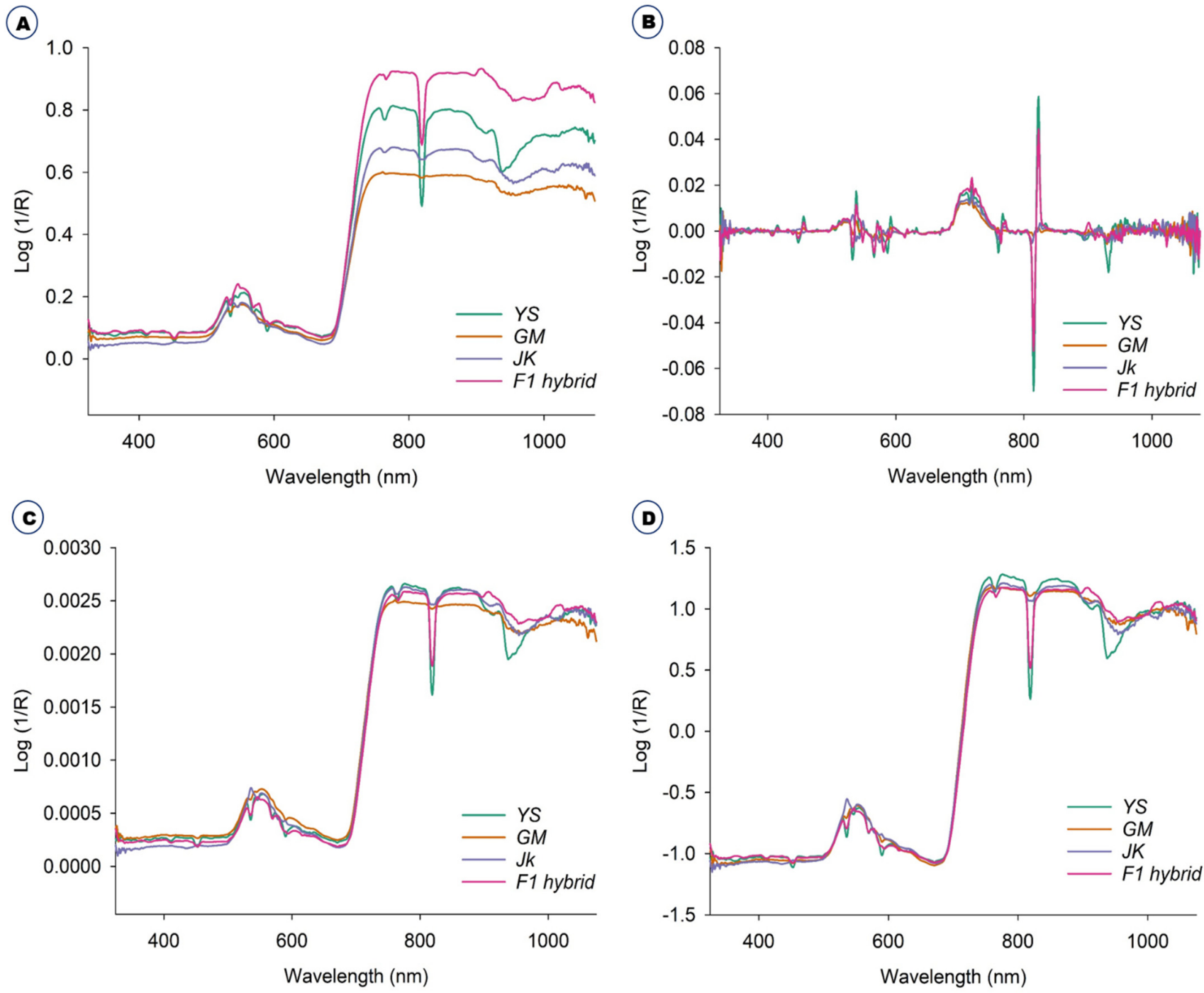

Figure 1. Average spectra obtained from all the plants. (A) Raw spectra. (B) Savitzky-Golay. (C) Normalization. (D) Standard Normal Variate.

There were differences in spectral reflectance but the majority of the spectra acquired from the four plants followed a similar pattern. The average reflectance difference between GM and non-GM B. napus, B. rapa, and F1 hybrids are assumed to be due to changes in hundreds of physicochemical constituents. The average spectra for all the plants, raw and preprocessed, with three different methods, namely, Savitzky-Golay, smoothing filter (21points), Normalization, and Standard Normal Variate, effectively visualized the differences (Figure 1). From the PCA-paired plot from PC1 to PC 6 (Figure 2A), all the different PCs showed some pattern of separation for the different samples, but PC1 vs. PC2 showed the greatest visual differences as shown in Figure 2B. Therefore, outlier detection was performed using these two PCs before commencing preprocessing for the machine learning classification methods. In PC1 and PC2 (Figure 2B) the B. napus plants could be clearly separated from the others. 

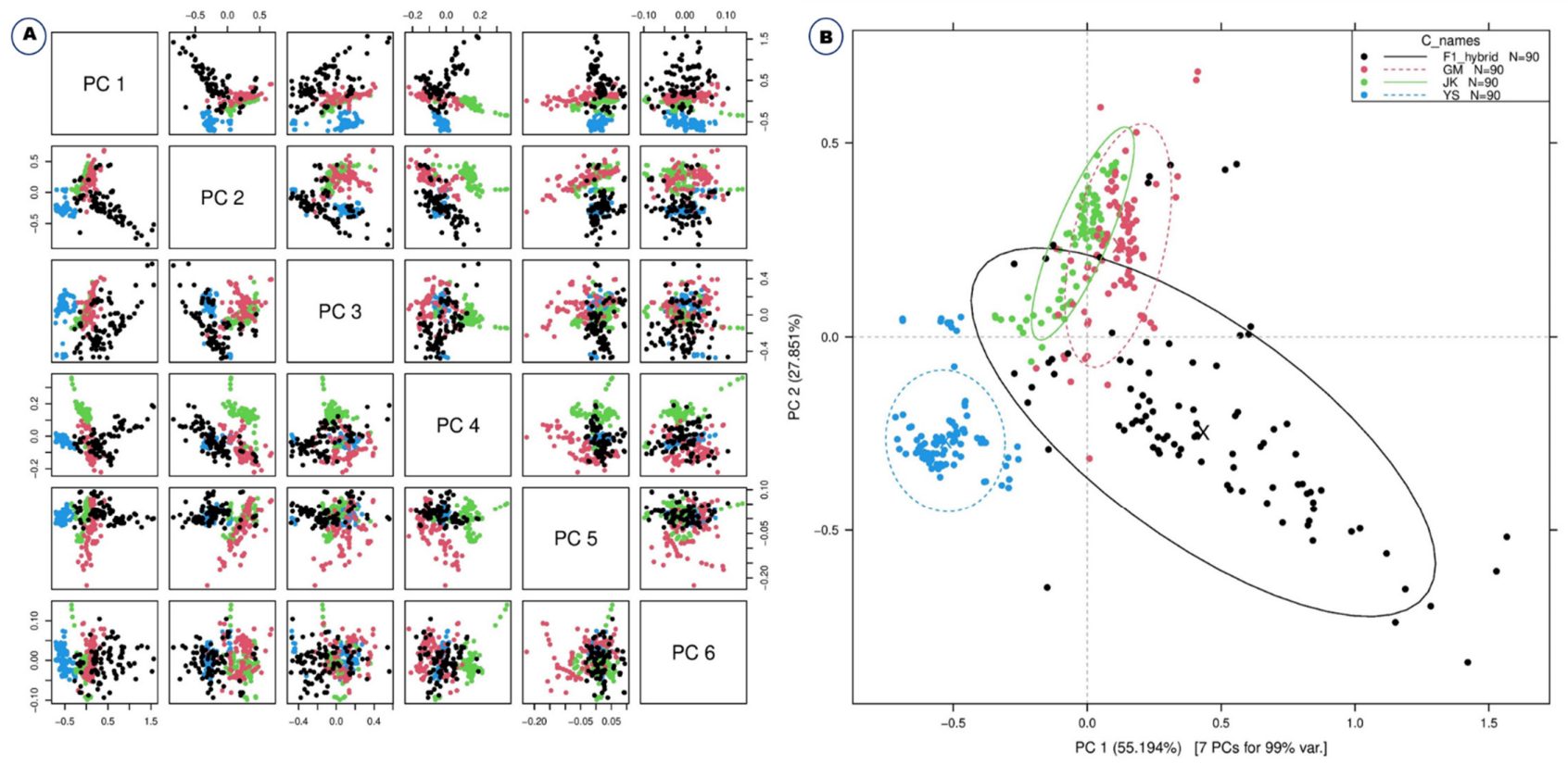

Figure 2. Principal Component Analysis (PCA) paired plot (A) and PC1 vs PC2 plot (B) for the visualization of B. napus, GM B. napus, B. rapa and F1 hybrids.

\subsection{Machine Learning Classification Methods}

Convolutional neural network (deep learning), linear discriminant analysis, gradient boosted trees, support vector machine, random forest, fast large margin, generalized linear model, and naive beyes were applied to the original spectral data and preprocessed spectra using normalization, standard normal variate (SNV), and Savitzky-Golay. The classification accuracy of various machine learning approaches combined with different preprocessing methods was calculated to identify the precise method for the discrimination of GM and non-GM B. napus, B. rapa and F1 hybrids (B. rapa X GM B. napus). This ranged from $70.5 \%$ to $100 \%$ based on the preprocessing and models applied to the spectra (Table 1). Among the different modelling approaches, Support Vector Machine, Linear Discriminant Analysis and Fast Large Margin were found to have higher accuracy in combination with different preprocessing methods (Savitzky-Golay/Support Vector Machine-100\%, and SavitzkyGolay/Linear Discriminant Analysis-99.8\%) (Table 1). In this study, normalization yielded the least performance accuracy method among the tested preprocessing methods (Table 1). Gradient Boosted Trees and Linear Discriminant analysis accuracies were $97.3 \%$ and $98.6 \%$, respectively, for normalization, whereas Naive Bayes and Fast Large Margin accuracies were $74.2 \%$ and $72.2 \%$, respectively. With Savitzky-Golay preprocessing, the accuracies of Support Vector Machine and Generalized Linear Model were 100\% and 97.9\%, respectively, while Naive Bayes and Random Forest were $87.5 \%$ and $89 \%$, respectively. In the case of Standard Normal Variate preprocessing, Support Vector Machine showed 98.4\% accuracy, Fast Large Margin 96.2\%, Generalized Linear Model 90.3\%, and Naive Bayes 81.2\% (Table 1). Effective discrimination of B. napus, GM B. napus, B. rapa and F1 hybrids using Linear Discriminant Analysis are shown in Figure 3. 
Table 1. Classification accuracy of the combinations of preprocessing and model for reflectance spectra from B. napus, GM B. napus, B. rapa and F1 hybrids.

\begin{tabular}{|c|c|c|c|c|}
\hline S. No & Model & Preprocessing & $\begin{array}{c}\text { Average Accuracy } \\
(\%)\end{array}$ & $\begin{array}{l}\text { Run Time } \\
\text { (ms) }\end{array}$ \\
\hline \multirow{4}{*}{1.} & \multirow{4}{*}{$\begin{array}{c}\text { Linear Discriminant } \\
\text { Analysis }\end{array}$} & Raw spectra & 78.3 & - \\
\hline & & Normalization & 98.6 & - \\
\hline & & Standard Normal Variate & 98.6 & - \\
\hline & & Savitzky-Golay & 99.8 & - \\
\hline \multirow{4}{*}{2.} & \multirow{4}{*}{$\begin{array}{c}\text { Support } \\
\text { Vector Machine }\end{array}$} & Raw spectra & 98.4 & 21,417 \\
\hline & & Normalization & 79.6 & 41,166 \\
\hline & & Standard Normal Variate & 98.4 & 22,074 \\
\hline & & Savitzky-Golay & 100.0 & 30,556 \\
\hline \multirow{4}{*}{3.} & \multirow{4}{*}{$\begin{array}{l}\text { Generalized } \\
\text { Linear Model }\end{array}$} & Raw spectra & 85.4 & 32,905 \\
\hline & & Normalization & 87.1 & 19,854 \\
\hline & & Standard Normal Variate & 90.3 & 26,768 \\
\hline & & Savitzky-Golay & 97.9 & 14,038 \\
\hline \multirow{4}{*}{4.} & \multirow{4}{*}{ Gradient Boosted Trees } & Raw spectra & 95.2 & 841,966 \\
\hline & & Normalization & 97.3 & 790,162 \\
\hline & & Standard Normal Variate & 97.3 & 988,233 \\
\hline & & Savitzky-Golay & 98.9 & 990,738 \\
\hline \multirow{4}{*}{5.} & \multirow{4}{*}{ Naive Bayes } & Raw spectra & 70.5 & 6546 \\
\hline & & Normalization & 74.2 & 6535 \\
\hline & & Standard Normal Variate & 81.2 & 6210 \\
\hline & & Savitzky-Golay & 91.4 & 6661 \\
\hline \multirow{4}{*}{6.} & \multirow{4}{*}{ Fast Large Margin } & Raw spectra & 93.6 & 37,002 \\
\hline & & Normalization & 71.2 & 38,845 \\
\hline & & Standard Normal Variate & 96.2 & 37,597 \\
\hline & & Savitzky-Golay & 98.9 & 17,611 \\
\hline \multirow{4}{*}{7.} & \multirow{4}{*}{ Random Forest } & Raw spectra & 79.0 & 31,558 \\
\hline & & Normalization & 86.6 & 30,336 \\
\hline & & Standard Normal Variate & 90.9 & 31,411 \\
\hline & & Savitzky-Golay & 91.4 & 31,590 \\
\hline \multirow{4}{*}{8.} & \multirow{4}{*}{$\begin{array}{c}\text { Convolutional Neural } \\
\text { Network } \\
\text { (Deep Learning) }\end{array}$} & Raw spectra & 91.4 & 7529 \\
\hline & & Normalization & 98.9 & 7123 \\
\hline & & Standard Normal Variate & 97.9 & 5850 \\
\hline & & Savitzky-Golay & 96.8 & 5450 \\
\hline
\end{tabular}

The efficiency of multiple preprocessing and machine learning methods on spectral datasets obtained from the assessed plants was statistically analyzed (Table 2). After cross-validation, the mean percentage of classification accuracy of each machine learning method in combination with various preprocessing methods revealed the significance of modeling for the discrimination of GM and non-GM B. napus, B. rapa and F1 hybrids (Table 2). Statistical analysis by ANOVA (Table 3 ), showed the sum of square and mean sum of square values of different preprocessing and machine learning methods with statistical significance at $p \leq 0.05$. With a combination of preprocessing and different machine learning methods used together, there was no significance with $p \geq 0.05$ ( $p$-value of 0.0925 ). The confusion matrix shows the degree of error in the classification of the assessed plants, which confirms that Savitzky-Golay combined with Support Vector Machine was the most effective method for the classification (Table 4). 

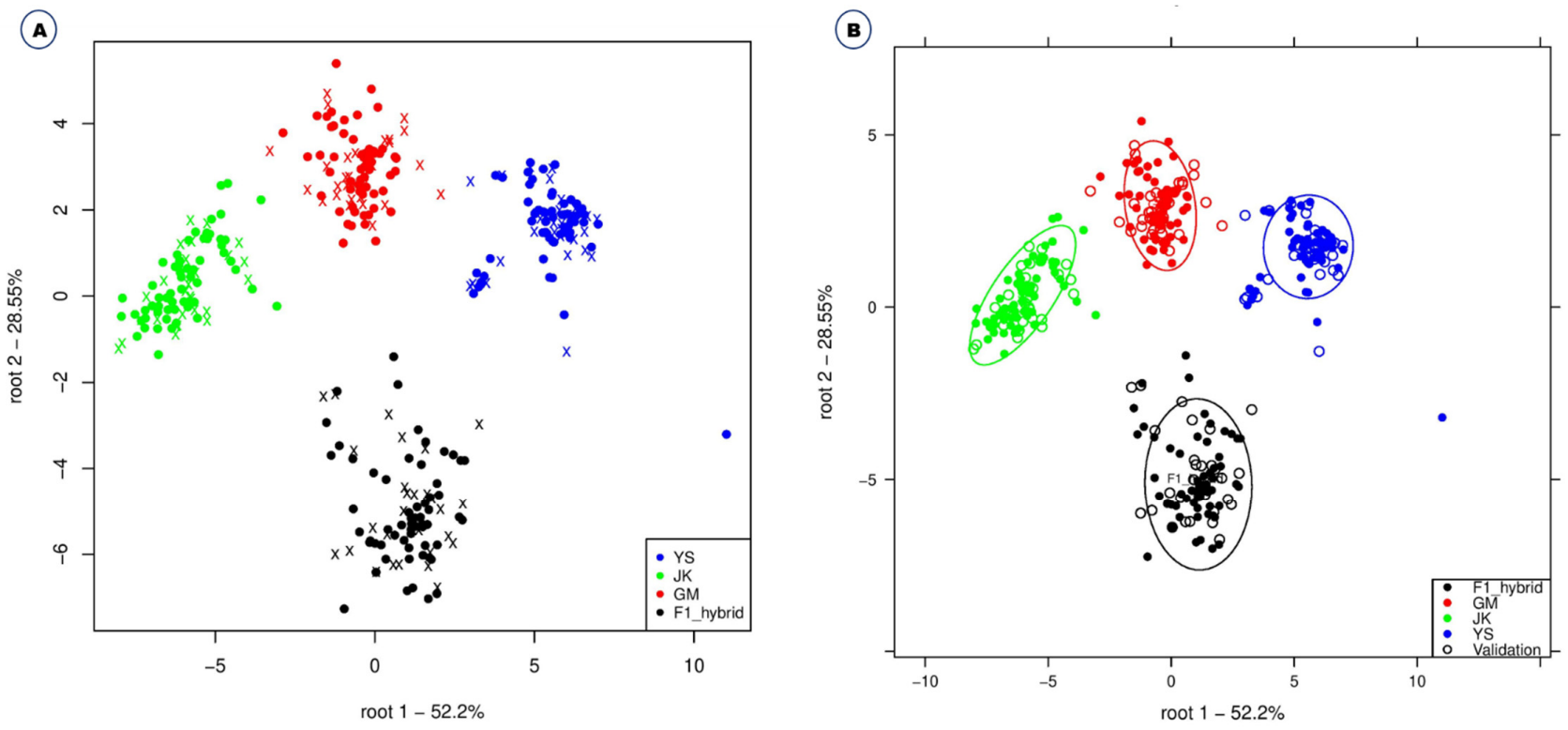

Figure 3. Linear Discriminant Analysis for the effective discrimination of B. napus, GM B. napus, B. rapa and F1 hybrids shown without confidence circles (A) and with confidence circle (B).

Table 2. Means of percentage of classification accuracy of different preprocessing and different classification model using reflectance spectra.

\begin{tabular}{|c|c|c|c|c|c|}
\hline \multirow{2}{*}{ Model } & \multicolumn{5}{|c|}{ Species Accuracy $(\% \pm S E)$} \\
\hline & Raw Spectra & Normalization & Savitzky-Golay & SNV & Significance \\
\hline Naive Bayes & $74.2 \pm 9.5$ & $74.5 \pm 3.3^{b}$ & $91.8 \pm 3.1$ & $82.7 \pm 4.9$ & ns \\
\hline $\begin{array}{c}\text { Generalized Linear } \\
\text { Model }\end{array}$ & $86.7 \pm 3.7$ & $87.2 \pm 2^{\mathrm{ab}}$ & $97.3 \pm 1.5$ & $91.3 \pm 6.3$ & ns \\
\hline Fast Large Margin & $94.1 \pm 4.4^{\mathrm{A}}$ & $73.1 \pm 4.4^{\mathrm{Bb}}$ & $99.2 \pm 0.8^{\mathrm{A}}$ & $96.3 \pm 3^{\mathrm{A}}$ & $* *$ \\
\hline $\begin{array}{c}\text { Convolutional Neural } \\
\text { Network }\end{array}$ & $92.8 \pm 3.5$ & $99.2 \pm 0.8 \mathrm{a}$ & $96.9 \pm 3.1$ & $98 \pm 1.2$ & ns \\
\hline Gradient Boosted Trees & $76.1 \pm 12.4$ & $85.6 \pm 6.4^{\mathrm{ab}}$ & $85.2 \pm 6.3$ & $59.6 \pm 22$ & ns \\
\hline Random Forest & $80.8 \pm 6$ & $87.2 \pm 2.3^{\mathrm{ab}}$ & $92.9 \pm 3.5$ & $91.5 \pm 3.3$ & ns \\
\hline $\begin{array}{l}\text { Support Vector } \\
\text { Machine }\end{array}$ & $98.4 \pm 1.6^{\mathrm{A}}$ & $80 \pm 3.6^{\mathrm{Bb}}$ & $100 \pm 0^{\mathrm{A}}$ & $98.3 \pm 1.7^{\mathrm{A}}$ & $* *$ \\
\hline significance & ns & $* *$ & ns & ns & \\
\hline
\end{tabular}

ns; not significant, ${ }^{* *}$ significant with the $p \leq 0.05$. Different alphabetical small and capital letters show the significance of the value in the order of column and row respectively.

Table 3. Analysis of variance of percentage of correctly classified B. napus, GM B. napus, B. rapa and F1 hybrids from four different preprocessing and four different classification model using reflectance spectra.

\begin{tabular}{cccccc}
\hline Source & df & SS & MS & F-Value & $p$-Value \\
\hline Preprocessing $(\mathrm{P})$ & 3 & 0.186074 & 0.062025 & 4.07 & 0.0095 \\
Model $(\mathrm{M})$ & 6 & 0.494012 & 0.082335 & 5.4 & $<0.0001$ \\
$\mathrm{P} \times \mathrm{M}$ & 18 & 0.426077 & 0.023671 & 1.55 & 0.0925 \\
Error & 84 & 1.280539 & 0.015245 & & \\
Total & 111 & 2.386702 & & & \\
\hline
\end{tabular}

df: degree of freedom. SS: sum of squares. MS: mean sum of squares. 
Table 4. Confusion matrix of species discrimination using better performing combinations of preprocessing methods and models.

\begin{tabular}{|c|c|c|c|c|c|}
\hline \multirow{2}{*}{$\begin{array}{c}\text { Savitzky-Golay/ } \\
\text { SVM }\end{array}$} & \multicolumn{4}{|c|}{ Classified as } & \multirow{2}{*}{$\begin{array}{c}\text { Average Accuracy } \\
\text { (\%) }\end{array}$} \\
\hline & B. napus & B. rapa & GM B. napus & F1 hybrid & \\
\hline B. napus & 43 & 0 & 0 & 0 & 100 \\
\hline GM B. napus & 0 & 42 & 0 & 0 & 100 \\
\hline B. rapa & 0 & 0 & 44 & 0 & 100 \\
\hline F1 hybrid & 0 & 0 & 0 & 56 & 100 \\
\hline Class recall (\%) & 100 & 100 & 100 & 100 & \\
\hline Normalize/ & \multicolumn{4}{|c|}{ Classified as } & Average Accuracy \\
\hline Convolutional Neural Network & B. napus & B. rapa & GM B. napus & F1 hybrid & $(\%)$ \\
\hline B. napus & 42 & 0 & 0 & 0 & 100 \\
\hline GM B. napus & 0 & 44 & 0 & 0 & 100 \\
\hline B. rapa & 0 & 0 & 40 & 0 & 100 \\
\hline F1 hybrid & 0 & 0 & 2 & 58 & 96.67 \\
\hline Class recall $(\%)$ & 100 & 100 & 95.24 & 100 & \\
\hline Savitzky-Golay/ & \multicolumn{4}{|c|}{ Classified as } & Average Accuracy \\
\hline Fast Large Margin & B. napus & B. rapa & GM B. napus & F1 hybrid & $(\%)$ \\
\hline B. napus & 42 & 0 & 0 & 0 & 100 \\
\hline GM B. napus & 0 & 44 & 0 & 0 & 100 \\
\hline B. rapa & 0 & 0 & 40 & 0 & 100 \\
\hline F1 hybrid & 0 & 0 & 2 & 58 & 96.67 \\
\hline Class recall $(\%)$ & 100 & 100 & 95.24 & 100 & \\
\hline
\end{tabular}

\subsection{Phenolic Acid Composition Analysis}

Initially, the contents of total phenolic acids, including methanol-soluble and methanolinsoluble phenolic acids in plant samples of B. napus, GM B. napus, B. rapa and the F1 hybrids, were analyzed using GC-MS analysis. Table 5 summarizes the content of each identified compound in the GM and non-GM B. napus, B. rapa and the F1 hybrids.

The major compounds assessed, i.e., p-hydoxybenzoic acid, vanillic acid, syringic acid, $p$-coumaric acid, ferulic acid and sinapic acid, were found in different concentrations among the assessed plants. Among the compounds, ferulic acid and sinapic acid were the most abundant compounds in the Brassica Sp. Ferulic acid was a little lower in B. rapa than in B. napus and F1 hybrids, whereas sinapic acid was found to be higher in B. rapa. Similar results were obtained from the biplot of PCA in which $B$. rapa. was separated from the other plants, B. napus, GM B. napus, and the F1 hybrids (Figure 4A). The loading plot indicated that ferulic acid was lower in B. rapa than in other species and hybrids (Figure 4B).
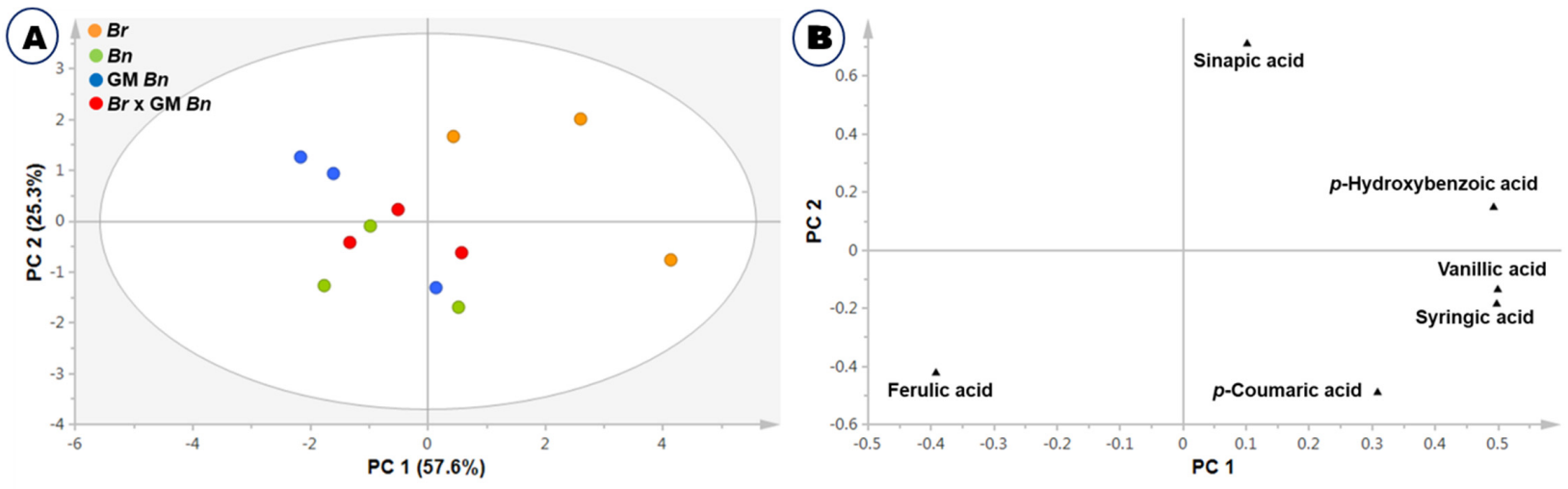

Figure 4. Score (A) and loading (B) plots of principal components 1 and 2 of the PCA results obtained from data on six total phenolic acids of four varieties. 
Table 5. Total phenolic acid composition analysis using GC-MS.

\begin{tabular}{|c|c|c|c|c|c|c|c|c|c|c|c|c|c|}
\hline \multirow{2}{*}{$\begin{array}{l}\text { S. } \\
\text { No }\end{array}$} & \multirow{2}{*}{$\begin{array}{l}\text { Phenolic } \\
\text { Acids }\end{array}$} & \multicolumn{3}{|c|}{$\begin{array}{l}\text { B. napus L. (Youngsan) } \\
\text { (ugg/g } \pm \text { SD) }\end{array}$} & \multicolumn{3}{|c|}{$\begin{array}{c}\text { GM B. napus L. (TG\#39) } \\
\text { (ug/g } \pm \text { SD) }\end{array}$} & \multicolumn{3}{|c|}{$\begin{array}{l}\text { B. rapa L. (Jangang) } \\
\quad(\text { ug } / \mathrm{g} \pm \mathrm{SD})\end{array}$} & \multicolumn{3}{|c|}{$\begin{array}{l}\text { B. rapa X GM B. napus } \\
\text { (F1 hybrid) (ug/g } \pm \text { SD) }\end{array}$} \\
\hline & & Soluble & Insoluble & Total & Soluble & Insoluble & Total & Soluble & Insoluble & Total & Soluble & Insoluble & Total \\
\hline 1 & $\begin{array}{l}p- \\
\text { hydroxybenzoic } \\
\text { acid }\end{array}$ & $2.2 \pm 0.4$ & $1.1 \pm 0.3$ & $3.3 \pm 0.6$ & $2.3 \pm 0.1$ & $0.9 \pm 0.1$ & $3.1 \pm 0.3$ & $4.1 \pm 0.7$ & $1.3 \pm 0.3$ & $5.4 \pm 1.0$ & $2.2 \pm 0.4$ & $1.3 \pm 0.8$ & $3.5 \pm 0.8$ \\
\hline 2 & vanillic acid & $3.0 \pm 0.6$ & $1.0 \pm 0.2$ & $4.0 \pm 0.7$ & $2.7 \pm 0.3$ & $1.1 \pm 0.2$ & $3.8 \pm 0.5$ & $3.9 \pm 0.8$ & $1.0 \pm 0.2$ & $4.9 \pm 0.9$ & $2.6 \pm 0.6$ & $1.0 \pm 0.1$ & $3.6 \pm 0.5$ \\
\hline 3 & syringic acid & $0.3 \pm 0.2$ & $0.3 \pm 0.2$ & $0.6 \pm 0.3$ & $0.3 \pm 0.2$ & $0.3 \pm 0.2$ & $0.6 \pm 0.3$ & $0.6 \pm 0.3$ & $0.4 \pm 0.3$ & $1.0 \pm 0.4$ & $0.3 \pm 0.2$ & $0.3 \pm 0.04$ & $0.6 \pm 0.2$ \\
\hline 4 & $\begin{array}{c}p \text {-coumaric } \\
\text { acid }\end{array}$ & $56.1 \pm 14.4$ & $6.9 \pm 0.7$ & $63.0 \pm 13.8$ & $28.1 \pm 17.1$ & $5.5 \pm 0.9$ & $33.7 \pm 18.0$ & $49.9 \pm 15.7$ & $12.7 \pm 1.5$ & $62.6 \pm 15.0$ & $56.2 \pm 6.4$ & $6.1 \pm 4.2$ & $62.3 \pm 10.5$ \\
\hline 6 & sinapic acid & $877.3 \pm 138.9$ & $26.5 \pm 4.8$ & $903.77 \pm 140.38$ & $935.8 \pm 427.3$ & $37.2 \pm 14.6$ & $973.06 \pm 441.83$ & $1439.2 \pm 518.4$ & $35.2 \pm 8.6$ & $1474.3 \pm 511.6$ & $923.6 \pm 73.0$ & $35.2 \pm 6.0$ & $958.80 \pm 78.64$ \\
\hline
\end{tabular}




\subsection{Partial Least Squares Regression (PLSR) Prediction of Phenolic Compounds}

Table 6 shows the PLSR prediction of phenolic compounds in all the plants. $p$-hydroxybenzoic acid, vanillic acid, syringic acid, $p$-coumaric acid, ferulic acid and sinapic acid could all be predicted with coefficients of determination after cross-validation (R2CV) above 0.89 and root mean square error after cross-validation (RMSECV) below $64.34 \mathrm{ug} / \mathrm{g}$. Only ferulic acid and sinapic acid had high RMSECV, and R2CV's higher than 0.89 . The results prove that all the measured phenolic compounds could be predicted with high accuracy using Vis-NIR spectroscopy. Among the different compounds, vanillic acid could be predicted with the highest R2CV of 0.93 (Figure 5) and the lowest RMSECV of 0.14 .

Table 6. PLSR prediction of phenolic compounds in all plants.

\begin{tabular}{cccccc}
\hline Phenolic Compound & $\begin{array}{c}\text { Latent } \\
\text { Variable }\end{array}$ & R2 & $\begin{array}{c}\text { RMSEC } \\
\text { (ug/g) }\end{array}$ & R2CV & $\begin{array}{c}\text { RMSECV } \\
\text { (ug/g) }\end{array}$ \\
\hline$p$-hydroxybenzoic acid & 4 & 0.93 & 0.26 & 0.91 & 0.28 \\
Vanillic acid & 4 & 0.94 & 0.13 & 0.93 & 0.14 \\
Syringic acid & 4 & 0.92 & 0.04 & 0.91 & 0.05 \\
$p$-coumaric acid & 4 & 0.91 & 3.68 & 0.89 & 4.03 \\
Ferulic acid & 4 & 0.94 & 58.91 & 0.93 & 64.34 \\
Sinapic acid & 4 & 0.94 & 57.89 & 0.93 & 63.64 \\
\hline
\end{tabular}

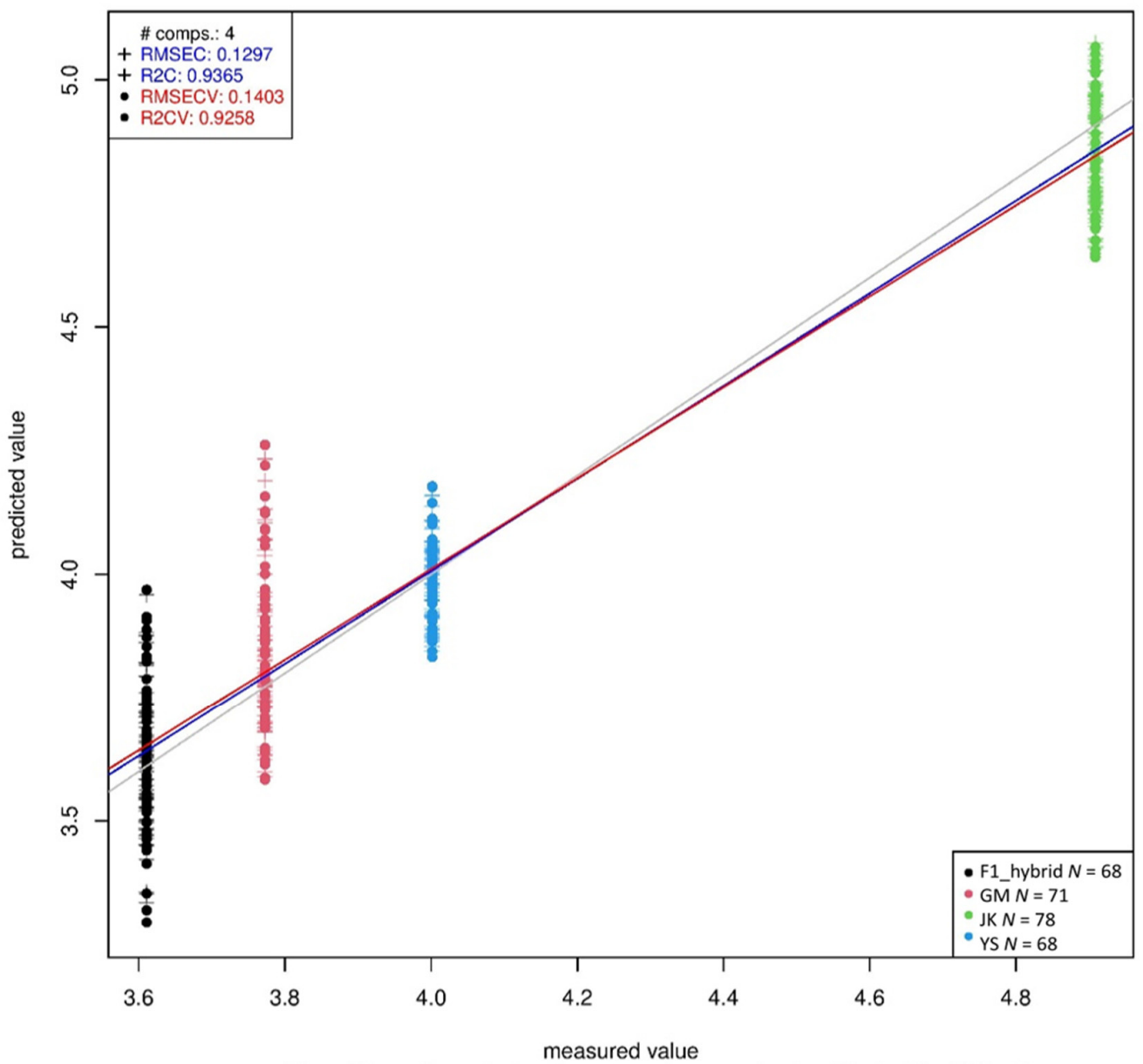

Figure 5. Partial least squares regression (PLSR) prediction of vanillic acid in all the plants.

\section{Discussion}

Physical qualities have a significant impact on product characteristics [25]. In this study, the morphological changes among B. napus, GM B. napus, B. rapa and F1 hybrids 
showed the variations in appearance. The F1 hybrids were found to have the structure of both B. napus and B. rapa. Vis-NIR spectroscopy is generally used for studying species discrimination of different plants and compositional changes of agricultural and food products $[26,27]$. The raw Vis-NIR spectra obtained by the handheld spectrophotometer cannot to be directly used because the number of spectra was high and the spectra were noisy $[18,28]$. Spectral data are mainly preprocessed to remove systemic noise to highlight the differences across the samples [18]. Utilization of different preprocessing methods simultaneously helps to achieve a different level of classification accuracy and provides an opportunity to find the best preprocessing method for a particular sample [18]. The selection of an optimum preprocessing method is difficult, since multiple different mathematical transformations are used, and different preprocessing methods provide different prediction results [29]. Generally, Vis-NIR spectra provide information on the chemical composition and physical state of the particular material, which provides structural information on the chemical functional groups of the molecules that constitute the molecular fingerprint of the sample [30,31]. Some characteristic peaks can be observed around 500-600 nm, the spectral range often being attributed to the presence of chlorophyll [32]; peaks also occur around $800 \mathrm{~nm}$. However, based simply on spectral reflectance, it is difficult to distinguish these samples. Therefore, it is necessary to use principal component analysis for effective classification using Vis-NIR spectroscopy in combination with advanced chemometrics methods. For the selection of ideal preprocessing methods for spectral data, the analysis should be done with several combinations of preprocessing, statistical and modelling methods, depending on the objective of the study. Discrimination accuracy can be improved differently depending on each method of preprocessing treatment [33].

The use of multiple modelling approaches in combination with different preprocessing methods resulted in the discrimination of GM and non-GM B. napus, B. rapa and F1 hybrids with different classification accuracy. Previously, several studies used a combination of NIR spectroscopy and multiple machine learning/chemometric methods for the effective discrimination of GM and non-GM crops with high classification accuracies $[18,22,31,34]$. Higher classification accuracy was found in the combination of Savitzky-Golay and Support Vector Machine methods. There are two known advantages of using derivatives of spectra: (1) increased resolution of overlapping peaks and reduced baseline variations, and (2) more effective modeling and testing than with the original spectra [35]. Among eight different chemometrics methods used, Support Vector Machine and Linear Discriminant Analysis were found to have the highest classification accuracy. SVM is a binary classification technique that is designed to solve a classification problem and is based on statistical learning theory. It has been shown to be an effective method for nonlinear classification, multivariate function estimation, and nonlinear regression $[36,37]$. Considering the LDA results, LDA grouped the plants on the basis of GM and non-GM B. napus, B. rapa and the F1 hybrids separately. The Support Vector Machine and Linear Discriminant Analysis methods were found to be more effective as compared to any other chemometric method. However, the ranking of the algorithms may not be accurate due to information leakage among different machine learning algorithms. Since the spectral data from the four different plant groups were simultaneously used for the study, the possibility of information leakage was quite high. However, the main outcome of the study is a novel, rapid method of discrimination of GM and non-GM B. napus and their interspecific hybrids (B. rapa X B. napus). Statistical analysis revealed the results were accurate and significant. ANOVA showed the ability of preprocessing methods and models to predict with a $p$ value of $p \leq 0.05$. Similar trends were also witnessed by Sohn et al. [38] in studying the six different Amaranthus sp. in the fields using Vis-NIR spectroscopy coupled with modelling methods.

Brassica crops are generally high in polyphenols, but the composition of phenolic compounds varies greatly between species and even between crops of the same species [39]. Flavonoids (mostly flavonols, but also anthocyanins) and hydroxycinnamic acids are the most common polyphenols found in Brassica sp. [40]. Polyphenolic compounds are essential components of a healthy diet. It has also been reported that they possess medicinal 
properties [41]. In general, as compared to other Brassica sp. B. napus has a higher level of phenolic compounds, especially ferulic acid and sinapic acid derivatives [42,43]. To confirm the validity of the NIR spectroscopy model, it is imperative to analyze the regression coefficient plots of the PLS models to check that the key wavelengths of the model are related to the spectroscopic signal of the interested constituent molecule [44,45]. Hence, the GC-MS analysis and the Vis-NIR Spectra were correlated with PLSR methods, and GM and non-GM crops were discriminated based on the polyphenolic compounds. The RMSECV levels of three hydroxybenzoic acids ( $p$-hydroxybenzoic, vanillic, and syringic acids) analyzed in this study were much lower compared to the three hydroxycinnamic acids ( $p$-coumaric acid, ferulic acid and sinapic acid). Recently, Peiris et al. [24] studied the discrimination of sorghum lines using NIR spectroscopy with different modelling methods and also the starch and protein content among the selected lines. They found that regression analysis resulted in the discrimination of lines according to seed starch contents.

\section{Materials and Methods}

\subsection{Plant Materials}

The seeds of the plants used in the study, such as B. napus L. 'Youngsan' and B. rapa L. ssp. pekinensis 'Jangkang' were obtained from the National Agrobiodiversity Center, Jeonju, Korea. GM B. napus (Youngsan) seeds with CAMV 35S-regulated bar gene and an early flowering gene (BrAGL20) were kindly provided by Yeon-Hee Lee, National Institute of Agricultural Sciences, Jeonju, Korea. For hybrid preparation, artificial hand pollination was done with B. rapa and GM B. napus and the seeds of F1 hybrids (B. rapa X GM B. napus) were used for further studies [8]. The hybrids were confirmed through a survival assay after $0.3 \%$ Bastar treatment, the phenotype of the hybrids, and polymerase chain reaction with partial 35 S promoter and BrAGL20 [8]. All the plants were grown in soil cups (Figure 6) and maintained in a controlled environment. This study was performed from May to July 2020 in the greenhouse of the National Institute of Agricultural Sciences, Jeonju, Korea.

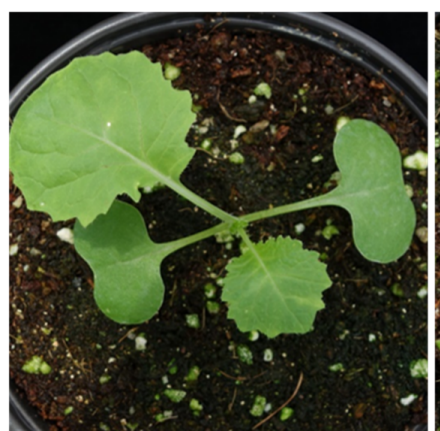

B. napus L.

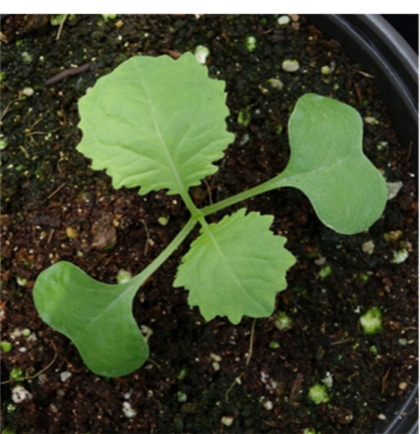

GM B. napus L.

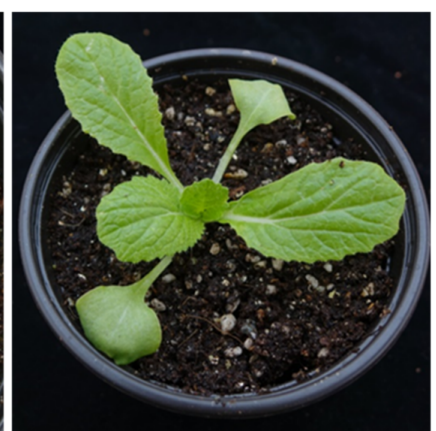

B. rapa $\mathrm{L}$.

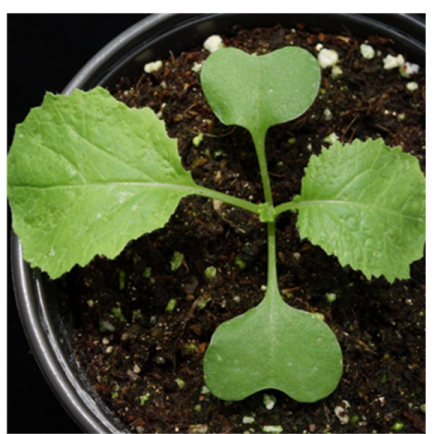

B. rapa $\times$ GM B. napus (F1 hybrid)

Figure 6. Representative photos of plants selected for the spectral analysis.

\subsection{Spectral Measurement and Preprocessing}

Vis-NIR diffuse reflectance spectra were collected with a handheld integrated portable spectral analyzer (FieldSpec ${ }^{\circledR}$ HandHeld 2, ASD Inc., Longmont, CO, USA), working in reflectance mode $(\log / \mathrm{R})$ in the range of $325-1075 \mathrm{~nm}$ with stepping of $1.5 \mathrm{~nm}$. The spectra were measured on the adaxial surface of the fully expanded leaves, which can easily capture the light. Three spectra were obtained from various parts of the leaf blade of fifty plants in each group. A total of $150(3 \times 50=150)$ spectra were collected from each group and used for further analysis. During each spectral acquisition, the Vis-NIR device's optical window was put in direct contact with the leaf's surface, ensuring that the sensor window was completely covered, according to the Sohn et al. [38]. Background signals appeared in the raw spectra of samples due to system parameters and environmental noise. To minimize spectral noise and improve effective information, different data preprocessing methods 
were employed, namely raw spectra, normalization, Savitzky-Golay, and Standard Normal Variate, which can reduce the noise and improve the accuracy of modelling approaches. The computations on preprocessing were done with Unscrambler ${ }^{\circledR} \mathrm{X}$ software, version 10.5.1 (CAMO ASA, Oslo, Norway).

\subsection{Modelling Methods and Statistical Analysis}

For the effective visualization, principal component analysis (PCA) was used to analyze patterns and variances in the dataset. This was to detect and remove outliers before developing the classification models. For the effective discrimination of spectral data, several machine learning methods were used. The modelling was performed with the software package RapidMiner studios Version 9.0.002 (Rapidminer, Inc., Boston, MA, USA). In the study, we used seven classification methods, namely, Linear Discriminant Analysis, Convolutional Neural Network (deep learning), Gradient Boosted Trees, Support Vector Machine, Random Forest, Generalized Linear Model, Fast Large Margin, and Naive Bayes to find the best modeling approach with higher classification accuracy. For each of the algorithms, the inputs were provided as the data points of the spectra and the classes were the identification labels of B. napus, GM B. napus, B. rapa and F1 hybrid (B. rapa X GM B. napus). The metaparameters were tuned according to the Sohn et al. [38] and Abdeni et al. [46] for the effective use of the machine learning methods through RapidMiner software package. The classification accuracy of the various machine learning approaches combined with different preprocessing methods were calculated for identifying the precise method for the discrimination of GM and non-GM B. napus, B. rapa and F1 hybrid between B. rapa and GM B. napus.

One-way analysis of variance (ANOVA) was performed when comparing means for testing the influence of the application of a scatter correction method, the eight classification algorithms, and the interaction of the two precious factors (preprocessing and machine learning methods). As a mean comparison method, Tukey's range test was used at a significance level of $p \leq 0.05$.

\subsection{Assessment of Phenolic Acid Contents}

To compare the spectral differences and chemical composition of GM and non-GM plants we assessed phenolic acid compounds using GC-MS analysis. The leaves of all the plants were collected as three biological replicates and then freeze-dried at $80{ }^{\circ} \mathrm{C}$ for at least $72 \mathrm{~h}$ and ground into a fine powder using a planetary mono mill (Pulverisette 6; Fritsch, Idar-Oberstein, Germany). The powder was stored at $-80{ }^{\circ} \mathrm{C}$ until analysis. Methanol-soluble and methanol -insoluble phenolic acids were extracted according to the procedure described by Park et al. [47]. The powdered samples $(0.01 \mathrm{~g})$ were extracted by incubating at $30{ }^{\circ} \mathrm{C}$ for $10 \mathrm{~min}$ with $1 \mathrm{~mL}$ of $85 \%$ methanol containing $2 \mathrm{~g} / \mathrm{L}$ butylated hydroxyanisole. After centrifugation at $13,000 \mathrm{rpm}$ for $10 \mathrm{~min}$ at $4{ }^{\circ} \mathrm{C}$, the supernatant and residue were analyzed to determine the quantities of soluble and insoluble phenolic acids, respectively. Hydrolysis was conducted with $1 \mathrm{~mL} 5 \mathrm{~N} \mathrm{NaOH}$ at $30{ }^{\circ} \mathrm{C}$ under nitrogen gas for $4 \mathrm{~h}$. All mixtures were extracted with ethyl acetate and evaporated. After derivatization by using pyridine and $N$-(tert-butyldimethylsilyl)- $N$-methyltrifluroacetamide with $1 \%$ tertbutyldimethylchlorosilane, sample $(1 \mu \mathrm{L})$ was injected into a 7890A gas chromatograph (Agilent, Atlanta, GA, USA) with a split ratio of 10, and separated on a $30 \mathrm{~m} \times 0.25-\mathrm{mm}$ i.d. fused silica capillary column coated with $0.25-\mu \mathrm{m}$ CP-SIL 8 CB low bleed (Varian Inc., Palo Alto, CA, USA). The column effluent was introduced into a Pegasus HT TOF mass spectrometer (LECO, St. Joseph, MI, USA). The detailed condition of GC-TOFMS was followed as described previously [47]. Partial least squares regression (PLSR) was used to develop models to regress on the concentrations of $p$-hydroxybenzoic acid, vanillic acid, syringic acid, $p$-coumaric acid, ferulic acid and sinapic acid in all the samples. For all predictions, the dataset was divided into calibration and validation once again, and k-fold cross-validation was used to test the predictive significance of the models. The statistical parameters used to evaluate the performance of the PLSR models were the root mean 
square error of calibration (RMSEC) and the coefficient of determination (R2C); in crossvalidation (RMSECV, R2CV). The optimum number of latent variables was determined based on the minimum RMSECV to minimize the probability of over fitting.

\section{Conclusions}

In conclusion, Vis-NIR spectroscopy coupled with machine learning methods effectively discriminated between B. napus and GM B. napus, as well as B. rapa and the F1 hybrids (B. rapa X GM B. napus). Among the different combinations of preprocessing and machine learning methods, the combination of Savitzky-Golay and Support Vector Machine was found to be the most effective method, with $100 \%$ classification accuracy. The correct classification accuracy of the validation tests was achieved at $100 \%$ in a spectral range of 325-1075 nm. Further, GC-MS analysis-based phenolic acid measurements and PLSR analysis showed that the results were significantly correlated with Vis-NIR spectroscopybased discrimination of GM and non-GM B. napus, B. rapa and F1 hybrids. Thus, it is suggested that this nondestructive technology can be used in the field for the rapid detection of unintentional releases of GM crops and their hybrids into the environment, and for effective management.

Author Contributions: Conceptualization: S.-I.S., Y.-J.O. and C.-S.N.; methodology: S.-I.S., S.P., Y.-J.O., S.-Y.P.; E.-K.S.; H.-J.K., T.-H.R. and Y.-S.C. formal analysis: S.-I.S., S.P., Y.-J.O.; J.-L.Z.Z. and W.-S.C.; data curation: S.-I.S., Y.-J.O. and C.-S.N.; writing—original draft preparation: S.-I.S., S.P. and J.-L.Z.Z.; visualization: S.P. and J.-L.Z.Z.; project administration: S.-I.S.; funding acquisition: S.-I.S. All authors have read and agreed to the published version of the manuscript.

Funding: This study was carried out with the support of "Research Program for Agricultural Science \& Technology Development and 2021 Post-doctoral Fellowship Program (Project No. PJ014943012021)", National Institute of Agricultural Sciences, Rural Development Administration, Korea.

Institutional Review Board Statement: Not applicable.

Informed Consent Statement: Not applicable.

Data Availability Statement: The data presented in the study are available on request from the corresponding author. The data are not available due to privacy and ethical reasons.

Conflicts of Interest: The authors declare no conflict of interest.

\section{References}

1. USDA. Oilseeds: World Markets and Trade; USDA: Washington, DC, USA, 2020. Available online: https://www.fas.usda.gov/data/ oilseeds-world-markets-and-trade (accessed on 18 October 2021).

2. Chen, R.; Shimono, A.; Aono, M.; Nakajima, N.; Ohsawa, R.; Yoshioka, Y. Genetic diversity and population structure of feral rapeseed (Brassica napus L.) in Japan. PLoS ONE 2020, 15, e0227990. [CrossRef]

3. Chalhoub, B.; Denoeud, F.; Liu, S.; Parkin, I.A.P.; Tang, H.; Wang, X.; Chiquet, J.; Belcram, H.; Tong, C.; Samans, B.; et al. Early allopolyploid evolution in the post-Neolithic Brassica napus oilseed genome. Science 2014, 345, 950-953. [CrossRef] [PubMed]

4. Lu, K.; Wei, L.; Li, X.; Wang, Y.; Wu, J.; Liu, M.; Zhang, C.; Chen, Z.; Xiao, Z.; Jian, H.; et al. Whole-genome resequencing reveals Brassica napus origin and genetic loci involved in its improvement. Nat. Commun. 2019, 10, 1154. [CrossRef]

5. Sun, F.; Fan, G.; Hu, Q.; Zhou, Y.; Guan, M.; Tong, C.; Li, J.; Du, D.; Qi, C.; Jiang, L.; et al. The high-quality genome of Brassica napus cultivar 'ZS 11'reveals the introgression history in semi-winter morphotype. Plant J. 2017, 92, 452-468. [CrossRef] [PubMed]

6. Zou, J.; Mao, L.; Qiu, J.; Wang, M.; Jia, L.; Wu, D.; He, Z.; Chen, M.; Shen, Y.; Shen, E.; et al. Genome-wide selection footprints and deleterious variations in young Asian allotetraploid rapeseed. Plant Biotechnol. J. 2019, 17, 1998-2010. [CrossRef]

7. Séguin-Swartz, G.; Beckie, H.J.; Warwick, S.I.; Roslinsky, V.; Nettleton, J.A.; Johnson, E.N.; Falk, K.C. Pollen-mediated gene flow between glyphosate-resistant Brassica napus canola and B. juncea and B. carinata mustard crops under large-scale field conditions in Saskatchewan. Can. J. Plant Sci. 2013, 93, 1083-1087. [CrossRef]

8. Sohn, S.I.; Oh, Y.J.; Lee, K.R.; Ko, H.C.; Cho, H.S.; Lee, Y.H.; Chang, A. Characteristics analysis of F1 hybrids between genetically modified Brassica napus and B. rapa. PLoS ONE 2016, 11, e0162103. [CrossRef]

9. Tu, Y.K.; Chen, H.W.; Tseng, K.Y.; Lin, Y.C.; Kuo, B.J. Morphological and genetic characteristics of F1 hybrids introgressed from Brassica napus to B. rapa in Taiwan. Bot. Stud. 2020, 61, 1. [CrossRef]

10. Vigeolas, H.; Waldeck, P.; Zank, T.; Geigenberger, P. Increasing seed oil content in oilseed rape (Brassica napus L.) by overexpression of a yeast glycerol-3-phosphate dehydrogenase under the control of seed-specific promoter. Plant Biotechnol. J. 2007, 5, 431-441. [CrossRef] 
11. Zhu, M.; Monroe, J.G.; Suhail, Y.; Villiers, F.; Mullen, J.; Pater, D.; Hauser, F.; Jeon, B.W.; Bader, J.S.; Kwak, J.M.; et al. Molecular and systems approaches towards drought-tolerant canola crops. New Phytol. 2016, 210, 1169-1189. [CrossRef]

12. Miki, B.L.; Labbé, H.; Hattori, J.; Ouellet, T.; Gabard, J.; Sunohara, G.; Charest, P.J.; Iyer, V.N. Transformation of Brassica napus canola cultivars with Arabidopsis thaliana acetohydroxyacid synthase genes and analysis of herbicide resistance. Theor. Appl. Genet. 1990, 80, 449-458. [CrossRef]

13. Szydłowska-Czerniak, A. Rapeseed and its products-sources of bioactive compounds: A review of their characteristics and analysis. Crit. Rev. Food Sci. Nutr. 2011, 53, 307-330. [CrossRef] [PubMed]

14. Beckie, H.J.; Hall, L.M.; Simard, M.-J.; Leeson, J.Y.; Willenborg, C.J. A framework for postrelease environmental monitoring of second-generation crops with novel traits. Crop Sci. 2010, 50, 1587-1604. [CrossRef]

15. Wilkinson, M.J.; Timmons, A.M.; Charters, Y.; Dubbels, S.; Robertson, A.; Wilson, N.; Scott, S.; O’Brien, E.; Lawson, H.M. Problems of risk assessment with genetically modified oilseed rape. In Proceedings of the Brighton Crop Protection Conference Weeds, Brighton, UK, 20-23 November 1995; pp. 1035-1044.

16. Yoshimura, Y.; Beckie, H.J.; Matsuo, K. Transgenic oilseed rape along transportation routes and port of Vancouver in western Canada. Environ. Biosaf. Res. 2006, 5, 67-75. [CrossRef]

17. Ahmed, F.E. Detection of genetically modified organisms in foods. Trends Biotechnol. 2002, 20, 215-223. [CrossRef]

18. Sohn, S.-I.; Pandian, S.; Oh, Y.-J.; Zaukuu, J.-L.Z.; Kang, H.-J.; Ryu, T.-H.; Cho, W.-S.; Cho, Y.-S.; Shin, E.-K.; Cho, B.-K. An overview of near infrared spectroscopy and its applications in the detection of genetically modified organisms. Int. J. Mol. Sci. 2021, 22, 9940. [CrossRef]

19. Cozzolino, D.; Smyth, H.E.; Gishen, M. Feasibility study on the use of visible and near-infrared spectroscopy together with chemometrics to discriminate between commercial white wines of different varietal origins. J. Agric. Food Chem. 2003, 51, 7703-7708. [CrossRef]

20. Roussel, S.A.; Hardy, C.L.; Hurburgh, C.R., Jr.; Rippke, G.R. Detection of Roundup Ready ${ }^{\mathrm{TM}}$ soybeans by near-infrared spectroscopy. Appl. Spectrosc. 2001, 55, 1425-1430. [CrossRef]

21. Luna, A.S.; da Silva, A.P.; Pinho, J.S.; Ferré, J.; Boqué, R. Rapid characterization of transgenic and non-transgenic soybean oils by chemometric methods using NIR spectroscopy. Spectrochim. Acta Part A Mol. Biomol. Spectrosc. 2013, 100, 115-119. [CrossRef] [PubMed]

22. Feng, X.; Zhao, Y.; Zhang, C.; Cheng, P.; He, Y. Discrimination of transgenic maize kernel using NIR hyperspectral imaging and multivariate data analysis. Sensors 2017, 17, 1894. [CrossRef] [PubMed]

23. Ning, K.; Ding, C.; Zhu, W.; Zhang, W.; Dong, Y.; Shen, Y.; Su, X. Comparative metabolomic analysis of the cambium tissue of non-transgenic and multi-gene transgenic poplar (Populus $\times$ euramericana 'Guariento'). Front. Plant Sci. 2018, 9, 1201. [CrossRef]

24. Peiris, K.H.; Wu, X.; Bean, S.R.; Perez-Fajardo, M.; Hayes, C.; Yerka, M.K.; Jagadish, S.V.; Ostmeyer, T.; Aramouni, F.M.; Tesso, T.; et al. Near infrared spectroscopic evaluation of starch properties of diverse sorghum populations. Processes 2021, 9, 1942. [CrossRef]

25. Ge, G.; Zheng, X.; Wu, J.; Ye, Z.; Shi, C. Analysis of the conditional correlations from different genetic systems between the protein content and the appearance quality traits of indica rice. J. Genet. Gen. 2007, 34, 129-137. [CrossRef]

26. Huang, H.; Yu, H.; Xu, H.; Ying, Y. Near infrared spectroscopy for on/in-line monitoring of quality in foods and beverages: A review. J. Food Eng. 2008, 87, 303-313. [CrossRef]

27. Beć, K.B.; Grabska, J.; Huck, C.W. Near-infrared spectroscopy in bio-applications. Molecules 2020, 25, 2948. [CrossRef]

28. Rinnan, Å.; Van Den Berg, F.; Engelsen, S.B. Review of the most common pre-processing techniques for near-infrared spectra. TrAC Trends Anal. Chem. 2009, 28, 1201-1222. [CrossRef]

29. Fernández-Cabanás, V.M.; Garrido-Varo, A.; Pérez-Marín, D.; Dardenne, P. Evaluation of pretreatment strategies for near-infrared spectroscopy calibration development of unground and ground compound feeding stuffs. Appl. Spectrosc. 2006, 60, 17-23. [CrossRef] [PubMed]

30. Cordella, C.; Moussa, I.; Martel, A.-C.; Sbirrazzuoli, N.; Lizzani-Cuvelier, L. Recent developments in food characterization and adulteration detection: Technique-oriented perspectives. J. Agric. Food Chem. 2002, 50, 1751-1764. [CrossRef]

31. Xie, L.; Ying, Y.; Ying, T.; Yu, H.; Fu, X. Discrimination of transgenic tomatoes based on visible/near-infrared spectra. Anal. Chim. Acta 2007, 584, 379-384. [CrossRef] [PubMed]

32. Smith, H.L.; McAusland, L.; Murchie, E.H. Don't ignore the green light: Exploring diverse roles in plant processes. J. Exp. Bot. 2017, 68, 2099-2110. [CrossRef]

33. Delwiche, S.R.; Reeves, J.B.; Reeves, I.J. The effect of spectral pre-treatments on the partial least squares modelling of agricultural products. J. Near Infrared Spectrosc. 2004, 12, 177-182. [CrossRef]

34. Hao, Y.; Geng, P.; Wu, W.; Wen, Q.; Rao, M. Identification of rice varieties and transgenic characteristics based on near-infrared diffuse reflectance spectroscopy and chemometrics. Molecules 2019, 24, 4568. [CrossRef] [PubMed]

35. Handbook of Near-Infrared Analysis; Burns, D.A.; Ciurczak, E.W. (Eds.) CRC Press: Boca Raton, FL, USA, 2007.

36. Gestal, M.; Gómez-Carracedo, M.P.; Andrade, J.M.; Dorado, J.; Fernández, E.; Prada, D.; Pazos, A. Classification of apple beverages using artificial neural networks with previous variable selection. Anal. Chim. Acta 2004, 524, 225-234. [CrossRef]

37. Xie, L.; Ying, Y.; Ying, T. Classification of tomatoes with different genotypes by visible and short-wave near-infrared spectroscopy with least-squares support vector machines and other chemometrics. J. Food Eng. 2009, 94, 34-39. [CrossRef] 
38. Sohn, S.-I.; Oh, Y.-J.; Pandian, S.; Lee, Y.-H.; Zaukuu, J.-L.Z.; Kang, H.-J.; Ryu, T.-H.; Cho, W.-S.; Cho, Y.-S.; Shin, E.-K. Identification of Amaranthus species using visible-near-infrared (vis-NIR) spectroscopy and machine learning methods. Remote Sens. 2021, 13, 4149. [CrossRef]

39. Podsedek, A. Natural antioxidants and antioxidant capacity of Brassica vegetables: A review. LWT-Food Sci. Technol. 2007, 40, 1-11. [CrossRef]

40. Cartea, M.E.; Francisco, M.; Soengas, P.; Velasco, P. Phenolic compounds in Brassica vegetables. Molecules 2011, 16, 251-280. [CrossRef] [PubMed]

41. Brglez Mojzer, E.; Knez Hrnčič, M.; Škerget, M.; Knez, Ž.; Bren, U. Polyphenols: Extraction methods, antioxidative action, bioavailability and anticarcinogenic effects. Molecules 2016, 21, 901. [CrossRef]

42. Khattab, R.; Eskin, M.; Aliani, M.; Thiyam, U. Determination of sinapic acid derivatives in canola extracts using high-performance liquid chromatography. J. Am. Oil Chem. Soc. 2010, 87, 147-155. [CrossRef]

43. Velasco, P.; Francisco, M.; Moreno, D.A.; Ferreres, F.; García-Viguera, C.; Cartea, M.E. Phytochemical fingerprinting of vegetable Brassica oleracea and Brassica napus by simultaneous identification of glucosinolates and phenolics. Phytochem. Anal. 2011, 22, 144-152. [CrossRef] [PubMed]

44. Dowell, F.E.; Maghirang, E.B.; Graybosch, R.A.; Berzonsky, W.A.; Delwiche, S.R. Selecting and sorting waxy wheat kernels using near-infrared spectroscopy. Cereal Chem. 2009, 86, 251-255. [CrossRef]

45. Wu, D.; Yong, H.; Shuijuan, F. Short-wave near-infrared spectroscopy analysis of major compounds in milk powder and wavelength assignment. Anal. Chim. Acta 2008, 610, 232-242. [CrossRef] [PubMed]

46. Abedini, R.; Ghanegolmohammadi, F.; PishkamRad, R.; Pourabed, E.; Jafarnezhad, A.; Shobbar, Z.-S.; Shahbazi, M. Plant dehydrins: Shedding light on structure and expression patterns of dehydrin gene family in barley. J. Plant Res. 2017, 130, 747-763. [CrossRef] [PubMed]

47. Park, S.Y.; Lee, S.Y.; Yang, J.W.; Lee, J.S.; Oh, S.D.; Oh, S.; Lee, S.M.; Lim, M.H.; Park, S.K.; Jang, J.S.; et al. Comparative analysis of phytochemicals and polar metabolites from colored sweet potato (Ipomoea batatas L.) tubers. Food Sci. Biotechnol. 2016, $25,283-291$. [CrossRef] [PubMed] 